\title{
A Web of Coagulotoxicity: Failure of Antivenom to Neutralize the Destructive (Non-Clotting) Fibrinogenolytic Activity of Loxosceles and Sicarius Spider Venoms
}

\author{
Dwin Grashof ${ }^{1}$, Christina N. Zdenek ${ }^{1}{ }^{\mathbb{D}}$, James S. Dobson ${ }^{1}{ }^{\mathbb{C}}$, Nicholas J. Youngman ${ }^{1}$, \\ Francisco Coimbra ${ }^{1}$, Melisa Benard-Valle ${ }^{2} \mathbb{D}$, Alejandro Alagon ${ }^{2}$ and Bryan G. Fry ${ }^{1, *(\mathbb{D}}$ \\ 1 Venom Evolution Lab, School of Biological Sciences, The University of Queensland, St. Lucia, QLD 4072, \\ Australia; d.g.b.grashof@gmail.com (D.G.); christinazdenek@gmail.com (C.N.Z.); \\ j.dobson@uq.edu.au (J.S.D.); n.youngman@uq.edu.au (N.J.Y.); francisco.cp.coimbra@gmail.com (F.C.) \\ 2 Departamento de Medicina Molecular y Bioprocesos, Instituto de Biotecnología, \\ Universidad Nacional Autónoma de México, Av. Universidad 2001, Cuernavaca, \\ Morelos 62210, Mexico; melitza61@gmail.com (M.B.-V.); alagon@ibt.unam.mx (A.A.) \\ * Correspondence: bgfry@uq.edu.au
}

Received: 16 December 2019; Accepted: 22 January 2020; Published: 30 January 2020

\begin{abstract}
Envenomations are complex medical emergencies that can have a range of symptoms and sequelae. The only specific, scientifically-validated treatment for envenomation is antivenom administration, which is designed to alleviate venom effects. A paucity of efficacy testing exists for numerous antivenoms worldwide, and understanding venom effects and venom potency can help identify antivenom improvement options. Some spider venoms can produce debilitating injuries or even death, yet have been largely neglected in venom and antivenom studies because of the low venom yields. Coagulation disturbances have been particularly under studied due to difficulties in working with blood and the coagulation cascade. These circumstances have resulted in suboptimal spider bite treatment for medically significant spider genera such as Loxosceles and Sicarius. This study identifies and quantifies the anticoagulant effects produced by venoms of three Loxoscles species (L. reclusa, L. boneti, and L. laeta) and that of Sicarius terrosus. We showed that the venoms of all studied species are able to cleave the fibrinogen $A \alpha$-chain with varying degrees of potency, with L. reclusa and $S$. terrosus venom cleaving the $\mathrm{A} \alpha$-chain most rapidly. Thromboelastography analysis revealed that only $L$. reclusa venom is able to reduce clot strength, thereby presumably causing anticoagulant effects in the patient. Using the same thromboelastography assays, antivenom efficacy tests revealed that the commonly used Loxoscles-specific SMase D recombinant based antivenom failed to neutralize the anticoagulant effects produced by Loxosceles venom. This study demonstrates the fibrinogenolytic activity of Loxosceles and Sicarius venom and the neutralization failure of Loxosceles antivenom, thus providing impetus for antivenom improvement.
\end{abstract}

Keywords: venom; antivenom; fibrinogen; coagulopathy; spider

Key Contribution: Loxosceles and Sicarius venom was shown to be fibrinogenolytic, with antivenom unable to neutralize these effects.

\section{Introduction}

Envenomations are complex medical emergencies that can have a range of deleterious effects upon any physiological target reachable by the bloodstream. Symptoms vary widely, depending on many 
factors, including the offending species. Most venom research has focused on snakes, with spiders being largely neglected due to small venom yields available for testing, as well as fewer reported fatalities from envenomations [1]. In addition, current venom research largely focuses on neurotoxic effects (as reviewed by [2]), as coagulation assays involve inherent difficulties and require working with unstable and expensive coagulation cascade enzymes. As a result of these circumstances, research into the coagulation disturbances produced by spider venoms has been particularly neglected. A lack of knowledge in this regard could lead to uninformed clinical management strategies for spider bites, as well as the persistent use of ineffective antivenoms.

One spider genus known to possess anticoagulant toxins is Loxosceles, which includes medically important species such as Loxosceles laeta and L. reclusa [3]. Loxosceles envenomation, or loxoscelism, is the most medically significant spider envenomation in several countries across the Americas, with lethalities on record, and, in particular, constitutes the third highest cause of all accidents by venomous animals in Brazil [4]. Loxoscelism typically results in localized erythema (redness of skin), and/or large areas of ulceration and necrosis [5]. When left untreated this can lead to intensive surgical removal of the dead skin (sometimes requiring skin grafts) and leave behind large scars, thus having economic and emotional impacts [6]. Local loxoscelism effects are a result of the sphingomyelinase D toxin (SMase D), which is a type of phospholipase D toxin in the venom. These dermonecrotic toxins are also the most studied and well-characterized components in Loxosceles [7,8].

In addition to local symptoms, in nearly half of the cases, loxoscelism can cause severe systematic medical problems, including hematological disturbances and renal injury, which can progress to hemolysis, thrombocytopenia, shock, disseminated intravascular coagulation, acute renal failure, and even death [1,4-6]. These hematological disturbances are most likely induced by metalloproteases, a few of which have been characterized such as Loxolysin A (20-28 kDa) and Loxolysin B (32-35 kDa) found in L. intermedia venom [9]. Recent $L$. laeta venom gland transcriptomics identified multiple Loxosceles astacin-like metalloproteases (LALPs) within the 20 to $25 \mathrm{kDa}$ range [10]. That study also showed intra-species variation in two L. laeta localities (Brazil and Peru): the Peruvian L. laeta had an additional LALP at approximately $24 \mathrm{kDa}$ and more glycosylation of LALPs. The hypothesis that the Peruvian L. laeta LALPs are more enzymatic compared to the Brazilian L. laeta LALPs was confirmed by their fibrinogenolytic activity [10]. These hematological effects are typically noticeable long after the bite incident. These LALPs, similar to the previously described metalloproteases, Loxolysin A and B, were first hypothesized to have digestive functions [11]. However, they may aid in the spread of cytotoxins in the venom by anticoagulant action which exacerbates tissue damage, as has been suggested to convergently occur in some elapid snakes such as spitting cobras (Naja spp.) [12-14].

Most Loxosceles venom studies and bite reports have focused on the necrotic effects of the venom, giving little attention to the systematic anticoagulant effects. Only a few studies have investigated the anticoagulant, fibrinogenolytic (fibrinogen degradation) effects of the venom $[3,9,15,16]$. Results from 1D SDS-PAGE fibrinogen-cleaving gels have revealed that the venom of multiple Loxosceles species cleaves either the $A \alpha$ chains or the $A \alpha$ - and $B \beta$-chains, depending on the study [9] or species [16] with the $\gamma$-chain unaffected. Proteomics revealed that multiple LALP isoforms are present, ranging from 24 to $29 \mathrm{kDa}$, in venoms from three different Loxosceles species [17]. By cleaving fibrinogen, fibrinogen levels are lowered and less available for thrombin to cleave into fibrin clots, thereby interfering with blood clotting and producing an anticoagulant effect. This produces coagulopathy, which is observed clinically in loxoscelism cases [5]. However, no studies to date describe the fibrinogenolytic properties of these LALPs across multiple species, nor quantified the extent and speed of fibrinogen cleavage. Similarly, it is unknown if the cleavage of fibrinogen by Loxosceles venoms produces a transient, weak clot due to a pseudo-procoagulant mechanism as seen in some snake venoms [18-20], or whether destructive cleavage occurs, as seen in some snake venoms [20,21] and anguimorph lizards [22]. Species in the related Sicarius genus are known to generate strong necrotic symptoms associated with SMase D-like toxins such as Loxosceles [23,24], but their action upon blood coagulation is known. 
Therefore, a knowledge gap exists about the potency of Loxosceles and Sicarius spider venoms upon human blood and the mechanism of coagulotoxic effects, particularly upon fibrinogen. Similarly, a major knowledge gap exists regarding the ability of available antivenoms to neutralize fibrinogenolytic effects of Loxosceles venoms. Most studies on Loxosceles antivenom, either using crude venom or recombinant toxins, focus on the necrotizing effects of the venom rather than coagulotoxic effects [25-29]. This is reflected in the antivenom production, with the immunizing mixture typically being recombinant spider sphingomyelinase $\mathrm{D}$ toxin, not crude (whole) venom due to the impracticality of collecting large quantities of spider venom. For example, Brazil consumes 22,000 ampoules of anti-loxoscelic serum per year, which would require $1.8 \mathrm{~kg}$ of venom extracted from approximately 36,000 spiders [8]. As such, to fill venom demand for sufficient antivenom production, antivenom manufacturers are forced to use recombinant toxins in the immunising mixture. While the resulting serum was shown to neutralise sphingomyelinase D [30], the recombinant toxins used in antivenom production represents only a subset of the toxin diversity present within the venoms. Therefore, it is likely that antivenom raised against sphingomyelinase D will not target LALPs nor prevent the coagulation disturbances caused by these toxins. One study showed a polyvalent serum from rabbits using a combination of SMase D toxins, hyaluronidases, and LALPs. The authors suggested that this serum was able to prevent fibrinogen alpha-chain digestion using $100 \mu \mathrm{L}$ of serum to target $3 \mu \mathrm{L}$ of L. intermedia venom [29]. This high serum:antivenom ratio indicates poor neutralization capacity of this antivenom.

In order to fill the knowledge gaps regarding the fibrinogenolytic activity responsible for coagulopathy, and the relative neutralization by antivenom, this study investigated the fibrinogenolytic effects on human plasma caused by crude venoms from the Loxosceles species L. boneti, L. laeta, and two different localities of L. reclusa (Oklahoma, USA (OK) and Tamaulipas, Mexico (TMP)), as well as the related species Sicarius terrosus. Our results have important implications for the clinical treatment of and antivenom treatment for loxoscelism.

\section{Results}

\subsection{Fibrinogen Digestion}

Fibrinogen gels revealed that some of the venoms efficiently cleaved the $A \alpha$-chain of fibrinogen but none of the study venoms cleaved the $B \beta$ - or $\gamma$-chains within the time period studied ( $6 \mathrm{~h}$ ) (Figure 1 ). Interspecies variation in venom potency was observed: $S$. terrorus cleaved the $\mathrm{A} \alpha$-chain most rapidly, whereas all localities of L. reclusa and L. laeta took longer to cleave the A $\alpha$-chain, and L. boneti was the slowest and only able to cleave $20 \%$ of the $\mathrm{A} \alpha$-chain (Figure 2). There was also a slight intraspecies variation among the L. reclusa localities. The $6 \mathrm{~h}$ control allowed us to attribute the A $\alpha$-chain digestion to the venom and not natural decay of fibrinogen since no change in fibrinogen was observed in the absence of venom between the 0 min and $6 \mathrm{~h}$. Interestingly, L. reclusa OK 1 and L. reclusa TMP 1 venoms exerted most of their activity within the first hour (e.g., $50 \%$ of the A $\alpha$-chain cleaved within an hour) compared to L. reclusa TMP 2 and L. laeta whose curves have a more gradual cleavage pattern. Sicarius terrosus venom cleaved all $\mathrm{A} \alpha$-chains within a $2 \mathrm{~h}$ incubation time with fibrinogen. 

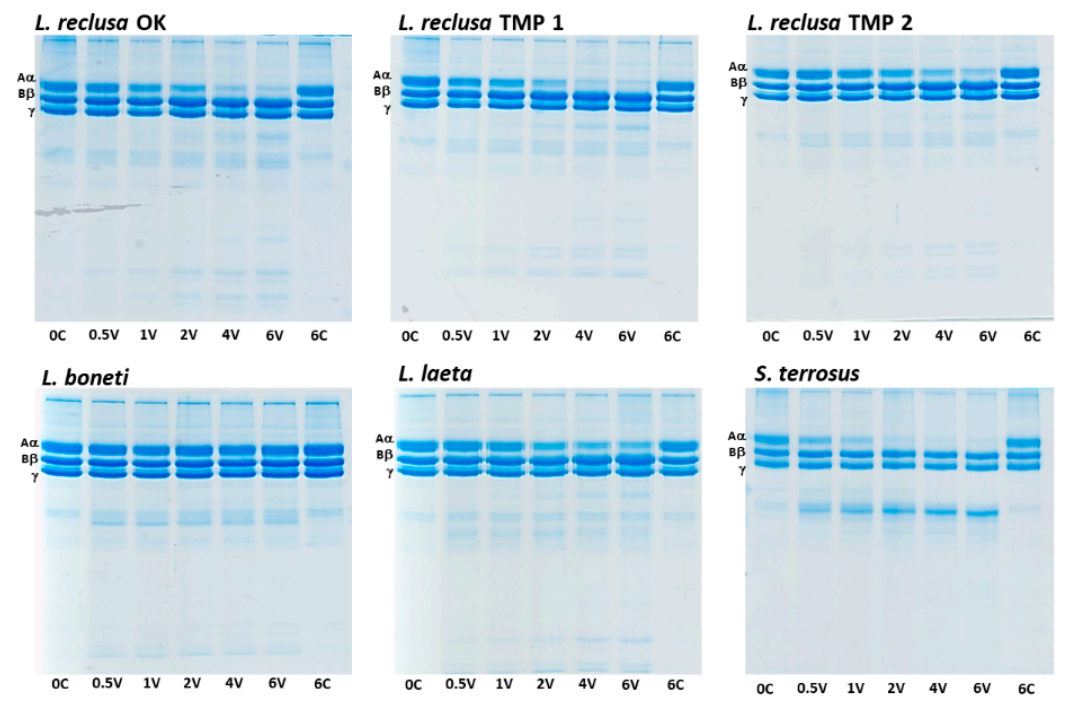

Figure 1. Representative one-dimensional (1D) SDS-PAGE gels showing time-dependent fibrinogen chain degradation $(\mathrm{A} \alpha, \mathrm{B} \beta$ or $\gamma)$ by venom $(0.1 \mu \mathrm{g} / \mu \mathrm{L})$ at $37^{\circ} \mathrm{C}$ over $6 \mathrm{~h}$. C: Negative controls using OK buffer as a blank in place of venom at $0 \mathrm{~min}$ and $6 \mathrm{~h}$ incubation times; $\mathrm{V}$ : Venom incubation over $\mathrm{X}$ hours; OK: Oklahoma; USA; TMP: Tamaulipas, Mexico.

Fibrinogen alpha chain cleaved

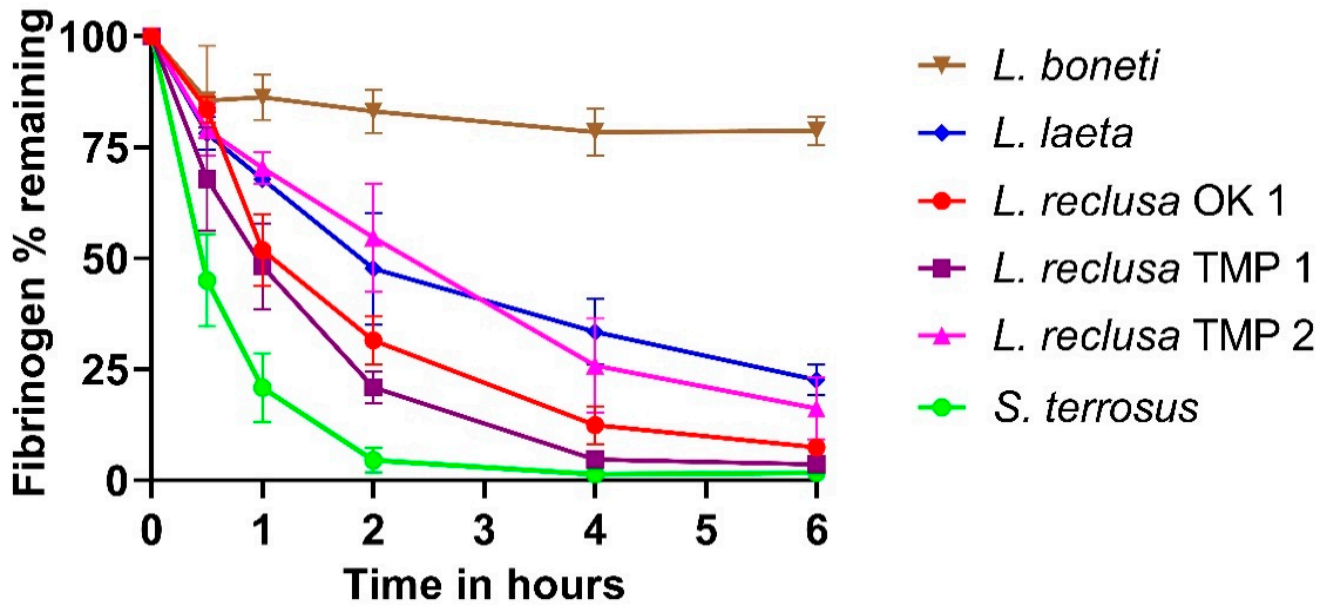

Figure 2. Graphical representation of percentage A $\alpha$-chain fibrinogen cleaved using the 1D SDS-PAGE gels from Figure 1. The percentage is derived from the color intensity of the bands, as quantified using ImageJ. Data points are $n=3$ and the error bars show the standard deviation. OK: Oklahoma; USA; and TMP: Tamaulipas, Mexico.

\subsection{Fibrinogen Thromboelastography}

Thromboelastography on human fibrinogen revealed that all L. reclusa localities slightly weakened the clot strength compared to the negative control (Figure 3). As expected, the venom of L. boneti did not differ from the negative control. Interestingly, despite $S$. terrosus venom rapidly cleaving the A $\alpha$-chain, thrombin was still able to form a strong clot once added to the cup after the incubation step. Similarly, L. laeta venom did not reduce clot strength. 
Venom and fibrinogen thromboelastography

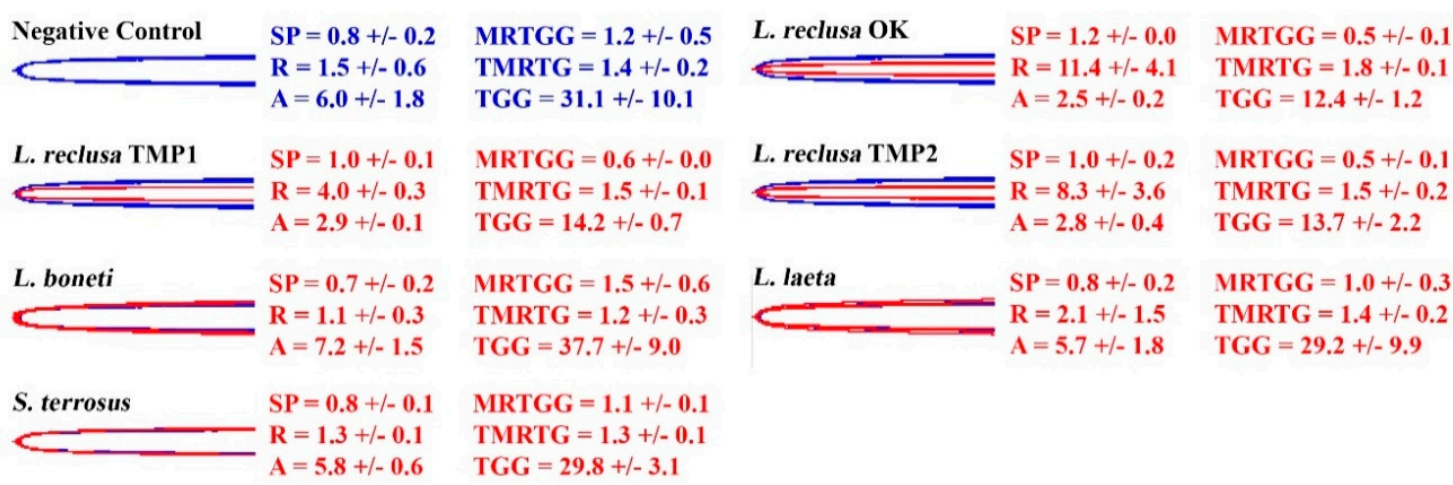

Figure 3. Overlaid thromboelastography traces showing the strength of fibrinogen clots with (red traces) and without (blue traces) venom. Blue traces: Negative controls (thrombin added after $30 \mathrm{~min}$ ). The wider the trace, the stronger the clot, and vice versa. SP: Split point, time taken until clot begins to form (min); R: Time for initial clot formation where formation is $\geq 2 \mathrm{~mm}$ (min); A: Amplitude of clot $(\mathrm{mm})$; MRTGG: Maximum rate of thrombus generation (dynes $\left./ \mathrm{cm}^{2} / \mathrm{s}\right)$; TMRTG: Time to maximum rate of thrombus generation (min); TGG: Total thrombus generation $\left(\right.$ dynes $\left./ \mathrm{cm}^{2}\right)$. Overlaid traces are $n=3$ for each set of controls or samples. Values are $n=3$ means and standard deviation.

\subsection{Antivenom Efficacy}

Antivenom was added to the fibrinogenolysis assay on TEG (thromboelastograph) for using three different antivenom end concentrations $(0.1 \%, 0.3 \%$, and $3.8 \%)$. Two out of the three antivenom controls had comparable clot strength values of a mean between 10.5 and 9.1 (Figure 4), while the highest concentration has a lower mean of $7.5+/-0.5$. Using both venom and antivenom all three end concentrations show similar clot strength values of a mean between 4.2 and $4.8 \mathrm{~mm}$ (Figure 4A). This is an increase compared to tests without antivenom where $L$. reclusa venoms caused a decrease in clot strength averaged between 2.5 and $2.9 \mathrm{~mm}$ (Figure 3).

However, it is also evident that the AV controls on average have stronger clots (compared to samples without the antivenom addition), which decreases in a stepwise manner over increasing AV concentrations. Comparing mean clot strengths of venom and venom $+3.8 \% \mathrm{AV}$ suggest a minor venom neutralizing effect of the antivenom, but only under the highest antivenom concentration (Figure 4B). These results are indicative of some contribution to fibrinogenolysis by the sphingomyelinase enzymes against which the antivenom is made. On the other hand, the ratio of remaining clot strength shows the slightest observable difference between fibrinogen and venom with or without added antivenom, but statistical tests show no significance between the two with a $p$-value of 0.26 (Figure 4C). This result indicates that a high venom:antivenom ratio of 2:1 is not able to effectively neutralize the venom and reduce its fibrinogenolytic capabilities, consistent with metalloprotease enzymes not being included in the antivenom immunizing mixture. 
A

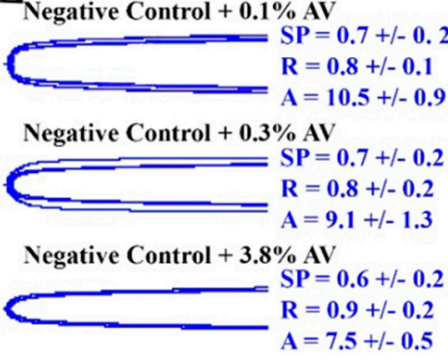

B

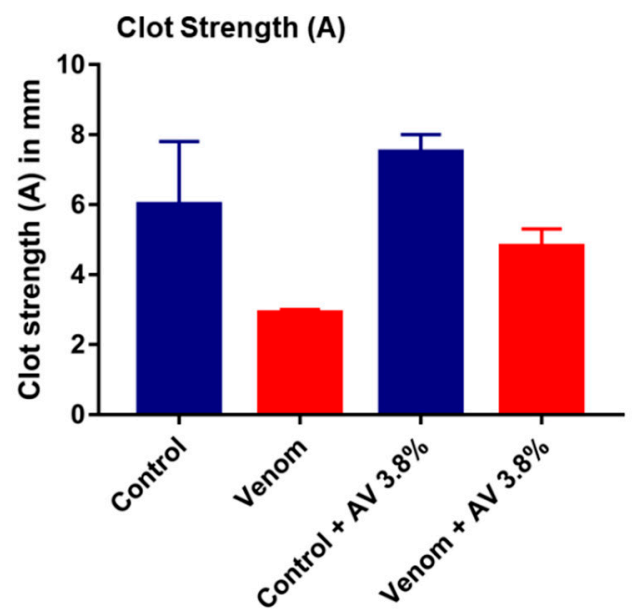
TGG $=48.3+/-7.6$ TGG $=39.2+/-2.5$
L. reclusa $\mathrm{TMP} 1+0.1 \% \mathrm{AV}$

MRTGG $=2.5+/-0.3$ TMRTG $=1.2+/-0.2$ TGG $=\mathbf{5 7 . 0}+/-5.9$

MRTGG $=2.0+/-0.3$ TMRTG $=1.2+/-0.2$

MRTGG $=1.5+/-0.2$

TMRTG $=1.2+/-0.1$

\section{C}

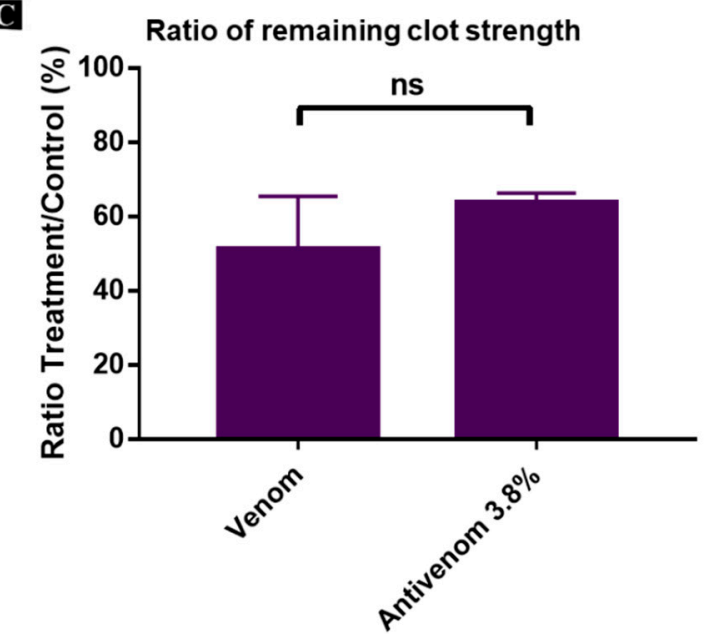

Figure 4. (A) Thromboelastography traces of fibrinogen clots produced by spider venom (red) overlaid with spider venom + antivenom (blue), relative to the negative controls (antivenom only). Three concentrations of antivenom were used. SP: Split point, time taken until clot begins to form (mins); R: Time to initial clot formation where formation is $>2 \mathrm{~mm}$ (mins); A: Amplitude of clot (mm); MRTGG: Maximum rate of thrombus generation (dynes $/ \mathrm{cm}^{2} / \mathrm{s}$ ); TMRTG: Time to maximum rate of thrombus generation ( $\mathrm{min})$; TGG: Total thrombus generation $\left(\right.$ dynes $\left./ \mathrm{cm}^{2}\right)$. Venom/control overlaid traces are $n=$ 3 for each set of controls or samples. Values are $n=3$ means and standard deviation. (B) Overview of clot strength reduction of only venom and venom + AV. Blue bars: Negative control clot strength values from Figure 3 and clot strength values using only 3.8\% AV control. Red bars: Clot strength values from L. reclusa TMP1 from Figure 3 and L. reclusa TMP1 $+3.8 \%$ AV. (C) Percentage of remaining clot strength relative to control after adding either L. reclusa TMP1 venom or L. reclusa TMP1 venom + $3.8 \% \mathrm{AV}$. The bars show the ratio of intact fibrinogen between the control and venom treatment for the first bar and ratio of intact fibrinogen between the 3.8\% AV control and 3.8\% AV + venom treatment. TMP: Tamaulipas, Mexico; Ns: Non-significant.

\subsection{D Gels of Crude Venom}

Crude venoms were analyzed by 1D SDS-PAGE gels under reducing conditions (Figure 5). All venoms showed similar banding patterns, except a band in the upper 50-75 kDa range being present in all spiders excluding $L$. boneti, which is the only investigated spider showing no fibrinogenolytic activity in the fibrinogen gels. 


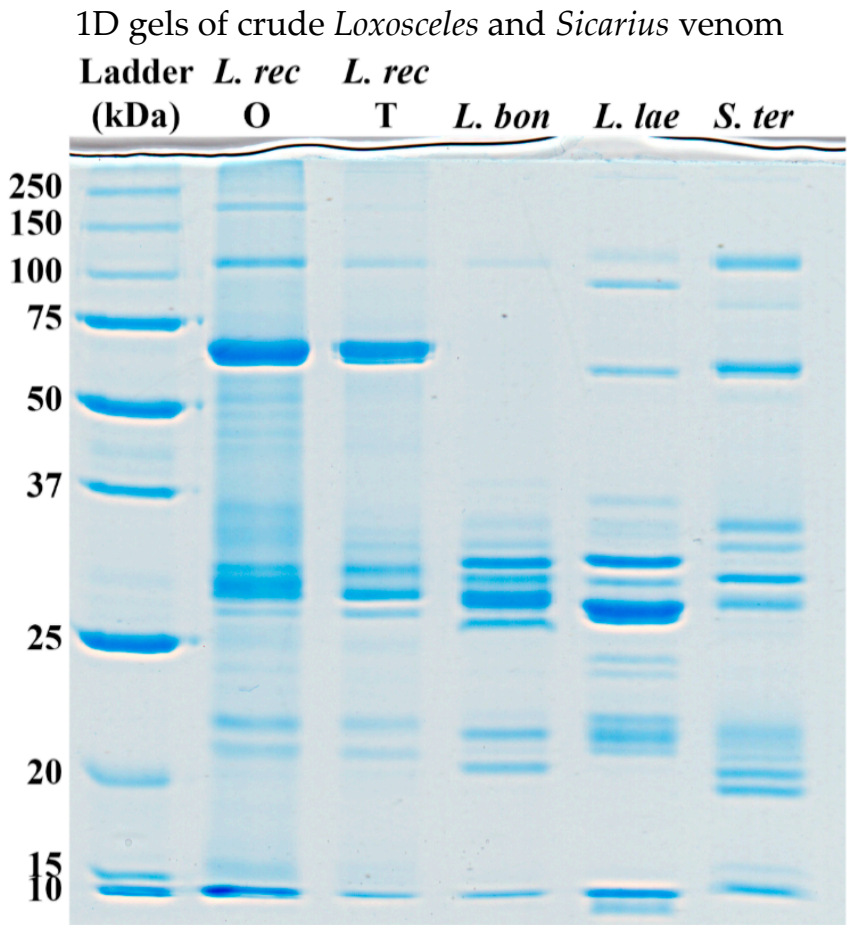

Figure 5. 1D SDS-PAGE (reduced) gel comparisons: L: Ladder; rec O: L. reclusa OK; L. rec T: $L$. reclusa TMP2; L. bon: L. boneti; L. lae: L. laeta; S. ter: S. terrosus; OK: Oklahoma; USA; and TMP: Tamaulipas, Mexico.

\section{Discussion}

Functional activity tests in the form of fibrinogen digestion in gels show the extent of the fibrinogenolytic properties of the venoms. These assays showed that all studied Sicariidae species were able to cleave only the A $\alpha$-chain, although $L$. boneti to a low extent. No cleavage activity was observed on the $B \beta$ - or $\gamma$-chains for all species. This is congruent with literature where L. intermedia was found to cleave the $A \alpha$-chain with no effect on the $B \beta$-chain [9]. However, another study showed L. intermedia venom cleaved both the $A \alpha$ - and the $B \beta$-chain, which is probably attributed to the relatively long $(16 \mathrm{~h})$ incubation period [16] compared to the present studdy $(6 \mathrm{~h})$. The extreme fibrinogenolytic effects of $S$. terrosus were unexpected since no previous studies have looked at fibrinogenolytic properties in their venom; however, a review on Sicarius sp. bites does state cases of widespread haemmorrhage [31], which may indicate fibrinogenolytic activity. The limited ability of $L$. boneti venom to cleave fibrinogen seems congruent with the absence of bite reports stating systematic bleeding, as this absence of bite reports suggest that $L$. boneti venom does not cause systemic bleeding that requires clinical treatment. This is in contrast with L. reclusa, since the observed fibrinogenolytic effects from L. reclusa venom are congruent with observed patient symptoms such as hemolysis, disseminated intravascular coagulopathy, and systematic bleeding as seen in confirmed L. reclusa bite reports [32].

The differential fibrinogenolytic functional effects of the venoms was reflected in fibrinogen gel degradation products. Where the Loxosceles venom produces multiple faint degradation product bands on 1D gels, Sicarius terrosus produces only one intense band (Figure 1). This indicates a difference in cleaving sites and activity of the responsible toxin and thus probably also the nature and severity of the symptoms. This could be very important for S. terrosus bite treatment with Loxosceles-specific antivenom since there is no specific $S$. terrosus antivenom in production. However, a recent study does show cross-reactivity of heterophilic antibodies for loxoscelism between multiple Loxosceles species and Sicarius terrosus [33].

Thromboelastography assays revealed that while L. reclusa had a moderate fibrinogenolytic activity of the A $\alpha$-chain in the fibrinogen gels, it produced a greatly reduced clot strength in TEG assays. In 
contrast, while $S$. terrosus showed relatively potent and fast fibrinogenolytic activity on the A $\alpha$-chain in the fibrinogen gels, it failed to reduce the clot strength in TEG assays. Inconsistency between fibrinogen gels and thromboelastography has been shown before within the varanids: the authors hypothesized that the speed of cleaving $A \alpha$-chains and presumably B $\beta$-chains explained the reduced clot strength [22]. However, S. terrosus venom cleaves the A $\alpha$-chain at a higher speed than L. reclusa venom and this is therefore unlikely to be the underlying reason for this observed inconsistency. Another explanation could be the cleaving site of their toxins and therefore, more importantly, the degradation product(s) of the reaction. As S. terrosus venom gives a single observable degradation product, compared to L. reclusa venom producing more complex (and thus faint) degradation products in the fibrinogen gels, this suggests that the fibrinogenolytic toxins in S. terrosus venom may cleave the A $\alpha$-chain in such a manner that it does not inhibit thrombin from producing a strong clot.

It is important to note that the $\mathrm{A} \alpha$-chain cleaving venom alone will not produce coagulation symptoms, as cleaving just the A $\alpha$-chain alone does not produce a fibrin clot [34-36]. Whereas, L. reclusa venom most likely cleaves the $\mathrm{A} \alpha$-chain in a destructive manner at multiple cleavage sites, thus preventing the resulting fibrin strands from being able to form a clot. The local hemorrhagic lesions caused by $S$. terrosus venom should, therefore, be explained, for example, by blood vessel damage caused by phospholipase $\mathrm{D}$ toxins also present in the venom.

To test for the ability of the SMase D-specific antivenom to neutralize the fibrinogenolytic toxins in the studied Sicariidae venoms, antivenom was added to thromboelastography assays. These assays revealed a minor increase of clot strength compared to L. recluse venom but only across all three concentrations of antivenom, indicating some cross-reactivity within the venom. The increasing ratio of venom:antivenom did not further increase the clot strength, even at a 2:1 venom:antivenom ratio. This is nevertheless unlikely to be a clinical increase in clot strength as shown by the ratio of remaining clot strength between the controls and the venom/venom:antivenom. Statistical tests show that this increased clot strength ratio of the venom:antivenom is not significantly different from the venom clot strength ratio, even more so indicating that this antivenom has no clinical neutralizing effect on the fibrinogenolytic toxins. This is not surprising since the antivenom was made using recombinant SMase D toxins, which are thought to not show any fibrinogenolytic activity. This assay revealed that, despite significant reductions described in loxoscelism using recombinant SMase D antivenom [28,30,37], those antivenoms are unlikely to provide any neutralization of fibrinogenolytic toxins and their associated systematic effects.

Surprisingly, the highest concentration of antivenom in the negative control showed a decrease in clot strength, where clot strength was negatively correlating with the volume of antivenom added to the sample on TEG. While the average strength of clots were overall higher with antivenom than the controls were without antivenom, the average clot strength did decrease in the controls as antivenom concentration increased. To our knowledge, this is the first time clot strength was measured to test any adverse effects that the antivenom itself might have on the clot strength of fibrinogen. However, since the concentration of antivenom in our tests was so high, it is unlikely that similar adverse effects in a clinical setting could be produced, as such antivenom levels would be exceedingly unlikely to be reached [38]. Thus, while biochemically interesting, these effects are not likely to be clinically relevant. The effects are likely due to a preservative or other stabilizing chemicals that have a nonspecific effect upon the fibrinogen due to the very high concentrations used in the last tests.

1D gels of Sicariidae venoms were congruent with those of previously studied crude venoms [23]. Gel bands across different species revealed major interspecific variation, and some minor intraspecific variation between the two different localities (L. reclusa OK and L. reclusa TMP) were also evident. Previous venom characterizations of related Sicariidae spiders focused on toxins in the 5-40 kDa range, which were reported to be a complex mixture of phospholipases-D, astacin-like metalloproteases, and inhibitor cystine knot (ICK) peptides [8,17]. This is congruent with 1D gels presented in this study, showing most intense bands in the 25-37 kDa range and fainter bands in the 20-25 kDa range for all species. Even more so, literature characterized most toxins in the 25-37 kDa range as phospholipase-D 
or metalloproteinase subtype Loxolysin B, and toxins in the 20-25 kDa range as metalloproteinase subtype Loxolysin A. This distinction in range categories is also visible in the gels obtained in this study. Of which Loxolysin B is previously shown using SDS-PAGE gels to have fibrinogenolytic activity [9]. Higher molecular weight bands in the 50-75 kDa range which largely correlate with the venom's ability to cleave fibrinogen A $\alpha$-chains (e.g., only present in L. reclusa, S. terrosus, and faintly in L. laeta) are characterized as either zinc metalloproteinases, found in the venom gland transcriptome of L. intermedia, or high molecular weight serine-proteinases, isolated from L. intermedia venom [39]. However, isolated serine-proteinases from L. intermedia venom were shown to have no fibrinogenolytic activity, making it likely that fibrinogenolysis is due to zinc metalloproteinases. Without protein identification and fractionation no definitive conclusions can be made about the underlying toxin or toxins causing the observed fibrinogenolytic effects of some of these Sicariidae venoms. Therefore, future studies should test fibrinogenolytic activity of Sicariidae venom fractions, as well as sequence the fibrinogen degradation products to elucidate any variability in fibrinogen splice sites.

Despite Loxosceles spiders bites resulting in complex medical emergencies $[32,40]$ the effects of spider venoms upon coagulation has been a neglected area of research. This study demonstrates the severity of and significant interspecies variation in fibrinogenolytic activity for four Sicariidae spider species, with $L$. reclusa also showing destructive (non-clotting) fibrinogenolytic effects by reducing clot strength. The available antivenom was unable to neutralize fibrinogenolytic toxins present in these spiders, thereby drawing attention to this functional activity and the treatment plans for the resulting systematic effects. In conclusion, this study provides data relevant to clinical treatment of envenomed patients, particularly regarding the source of systematic afibrinogenemia effects and the absence of proper systematic-loxoscelism treatment to prevent these possibly deadly effects.

\section{Materials and Methods}

\subsection{Venom Samples}

Spider species represented in this research were Loxosceles reclusa (one sample from Oklahoma, USA and two samples from Tamaulipas, Mexico, referred to as OK and TMP 1 and 2, respectively), L. boneti, L. laeta, and Sicarius terrosus. Freeze-dried venom from L. reclusa (gland extracts) and L. boneti (milked venoms) were obtained from the UNAM collection of author AA and the venom from L. laeta and S. terrosus was obtained from VenomTech and stored at $-80{ }^{\circ} \mathrm{C}$ until use. Venom aliquots were solubilized in cold deionized water and centrifuged for $15 \mathrm{~min}$ at $4{ }^{\circ} \mathrm{C}(14,000 \mathrm{RCF})$. Afterward, the supernatant was collected and protein concentrations measured using a ThermoFisher Scientific (Waltham, MA, USA) NanoDrop ${ }^{\mathrm{TM}}$ spectrophotometer. Working stocks of $1 \mathrm{mg} / \mathrm{mL}$ were made with $50 \%$ deionized water and $50 \%$ glycerol, and then stored at $-20{ }^{\circ} \mathrm{C}$.

\subsection{Human Fibrinogen}

Human fibrinogen (Lot\#F3879, Sigma Aldrich, St. Louis, MO, USA) was reconstituted in an enzyme running buffer $(150 \mathrm{mM} \mathrm{NaCl}, 50 \mathrm{mM}$ Tri- $\mathrm{HCl}(\mathrm{pH} 7.3))$ to a concentration of $4 \mathrm{mg} / \mathrm{mL}$. The solution was then flash-frozen in liquid nitrogen as $1 \mathrm{~mL}$ aliquots and stored at $-80^{\circ} \mathrm{C}$ until required, where it was then defrosted in a water bath at $37^{\circ} \mathrm{C}$ for $5 \mathrm{~min}$.

\subsection{Antivenom}

In this study, we used the AAA anti-arachnid antivenom (Study drug: AAA2013-BB-IND 15757; Batch number 3IT08001; protein concentration of $18.83 \pm 0.03(n=3))$. As per manufacturer's instructions, the antivenom was made up in $2 \mathrm{~mL}$ deionized water and inverted until dissolved completely. Antivenom was centrifuged (10 $\left.\mathrm{min}, 4{ }^{\circ} \mathrm{C}, 14,000 \mathrm{RCF}\right)$, and the supernatant collected stored at $4{ }^{\circ} \mathrm{C}$. Antivenom working stocks ( $2.6 \%$ and $7.5 \%$ antivenom) were made by diluting antivenom with an Owren Koller (OK) Buffer (Stago catalog \#00360) and then stored at $4{ }^{\circ} \mathrm{C}$. 


\subsection{Fibrinogen 1D SDS-PAGE Electrophoresis and Gel Image Analysis}

The ability of the spider venoms to cleave fibrinogen chains was investigated by using an adapted protocol previously published by this lab [41-43]. Details of the gel are as follows: $3.3 \mathrm{~mL}$ deionized water, $4.0 \mathrm{~mL} \mathrm{30 \%}$ acrylamide mix, $2.5 \mathrm{~mL} 1.5 \mathrm{M}$ Tris- $\mathrm{HCl}, \mathrm{pH} 8.8,100 \mu \mathrm{L} \mathrm{10 \%} \mathrm{SDS,} 100 \mu \mathrm{L} \mathrm{10 \%} \mathrm{APS,}$ and $4 \mu \mathrm{L}$ TEMED (resolving/running gel); $1.4 \mathrm{~mL}$ deionized water, $330 \mu \mathrm{L} \mathrm{30 \%} \mathrm{acrylamide} \mathrm{mix,} 250 \mu \mathrm{L}$ $0.5 \mathrm{M}$ Tris- $\mathrm{HCl}, \mathrm{pH}$ 6.8, $20 \mu \mathrm{L} \mathrm{10 \%} \mathrm{SDS,} 20 \mu \mathrm{L}$ 10\% APS, $2 \mu \mathrm{L}$ TEMED (stacking gel). Resolving gel was cast first and the running gel was added after the resolving gel was solidified.

Spider venom and fibrinogen were prepared as described above. For this assay $43 \mu \mathrm{L}$ of $4 \mathrm{mg} / \mathrm{mL}$ fibrinogen was mixed with $107 \mu \mathrm{L}$ of an enzyme running buffer, making it $150 \mu \mathrm{L}$ of $1 \mathrm{mg} / \mathrm{mL}$ fibrinogen. Of that, $10 \mu \mathrm{L}$ was aliquoted for the $0 \mathrm{~min}$ control and $20 \mu \mathrm{L}$ was aliquoted and incubated for $6 \mathrm{~h}$ at $37^{\circ} \mathrm{C}$ as a $6 \mathrm{~h}$ control to account for any evaporative loss. To reach a final ratio of 1:10 venom/fibrinogen in the assay, $13.3 \mu \mathrm{L}(133 / 10=13.3)$ of $1 \mathrm{mg} / \mathrm{mL}$ venom was added. The sample was then incubated at $37^{\circ} \mathrm{C}$ for $6 \mathrm{~h}$ while $10 \mu \mathrm{L}$ of the sample was aliquoted out for each of the following time points: $30 \mathrm{~min}$, $1,2,4$, and $6 \mathrm{~h}$. $10 \mu \mathrm{L}$ of the aliquoted sample was added to $10 \mu \mathrm{L}$ of buffer dye ( $5 \mu \mathrm{L}$ of $4 \times$ Laemmli sample buffer (BioRad, Hercules, CA, USA) and $5 \mu \mathrm{L}$ of $100 \mathrm{mM}$ DTT (Sigma-Aldrich, St. Louis, MO, USA) in deionized water). This was also done for the $0 \mathrm{~min}$ and $6 \mathrm{~h}$ controls which serve as untreated control lanes. Each aliquot was boiled at $100{ }^{\circ} \mathrm{C}$ for $4 \mathrm{~min}$, directly after it was mixed with the buffer dye. Furthermore, a venom-only control lane was made by adding $6 \mu \mathrm{L}$ of $1 \mathrm{mg} / \mathrm{mL}$ venom to $54 \mu \mathrm{L}$ of an enzyme running buffer for a final ratio of 1:10 venom/enzyme running buffer. $10 \mu \mathrm{L}$ of the venom control was added to $10 \mu \mathrm{L}$ of buffer dye and boiled the same way as the other aliquots. Each venom was tested in triplicate, resulting in three separate gels per venom used for analysis.

The aliquots were then loaded into a 1D SDS-PAGE gel using the following set up: Lane 1: $0 \mathrm{~min}$ untreated fibrinogen control; Lane 2: 30 min venom: + fibrinogen incubation; Lane 3: $1 \mathrm{~h}$ venom + fibrinogen incubation; Lane 4: $2 \mathrm{~h}$ venom + fibrinogen incubation; Lane 5: $4 \mathrm{~h}$ venom + fibrinogen incubation; Lane 6: $6 \mathrm{~h}$ venom + fibrinogen incubation; Lane 7: $6 \mathrm{~h}$ untreated fibrinogen control incubation; Gels were run in $1 \times$ gel running buffer at room temperature at $120 \mathrm{~V}$ until the dye neared the bottom of the gel cast $[18,43,44]$. All gels were run in triplicate under the same conditions. Afterwards, gels were stained using colloidal Coomassie brilliant blue G250 (34\% methanol (VWR Chemicals, Tingalpa, QLD, Australia), 3\% orthophosphoric acid (Merck, Darmstadt, Germany), $170 \mathrm{~g} / \mathrm{L}$ ammonium sulfate (Bio-Rad, Hercules, CA, USA), $1 \mathrm{~g} / \mathrm{L}$ Coomassie blue G250 (Bio-Rad, Hercules, CA, USA), and destained overnight using deionized water.

Gels were analyzed using the publicly available software ImageJ (V1.51r, Java 1.6.0_24, National Institutes of Health, Bethesda, Maryland, USA) [45]. To quantify fibrinogen cleavage, all gel images were scanned using a standard printer/scanner and loaded into ImageJ. Images were changed to 32-bit, and bands were emphasized using the 'Adjust Brightness/Contrast' option. To quantify the intensity of the bands, a box was drawn over the first control and was selected as the first lane using 'Analyze -> Gels $->$ Select first lane'. Sequential lanes were selected by placing boxes on the remaining lanes and using the 'Analyze -> Gels -> Select next lane' option, and the intensity of each band was plotted using the 'Analyze -> Gels -> Plot lanes' function. The individual peaks (representing the intensity of the $\mathrm{A} \alpha-, \mathrm{B} \beta-$, and $\gamma$ - chains, respectively) were separated with the "Draw line" function and quantified using the "Wand" function on each peak which produces an area under the curve value representing the intensity of a band. These values were entered into Windows Excel 2016, the average taken of triplicates, and the data graphed with standard deviation using GraphPad PRISM 7.0 (GraphPad Prism Inc., La Jolla, CA, USA).

\subsection{Thromboelastography}

To test the ability of venoms to reduce clot strength, a Thrombelastograph ${ }^{\circledR}$ Haemostasis System 5000 (Haemonetics ${ }^{\circledR}$, Haemonetics Australia Pty Ltd., North Ryde, Sydney 2113, Australia) was used in combination with Version 4 TEG Analytical Software (TAS ${ }^{\mathrm{TM}}$ ). This machine measures the elasticity, strength, and stability of the formed clot using a cup and pin, where the forming clot in the rotating 
cup creates tension on a torsion wire inside a fixed pin which can be transduced into values used to measure the clot. Important values are SP: Split point, time taken until clot begins to form (min); R: Time to initial clot formation where formation is $\geq 2 \mathrm{~mm}$ (mins); A: Amplitude of clot (mm); MRTGG: Maximum rate of thrombus generation (dynes $/ \mathrm{cm}^{2} / \mathrm{s}$ ); TMRTG: Time to maximum rate of thrombus generation ( $\mathrm{min})$; TGG: Total thrombus generation $\left(\right.$ dynes $\left./ \mathrm{cm}^{2}\right)$. Assays were adapted from previous published protocols $[18,19,21,42]$.

To maintain similar ratios as previously validated protocols, for this assay $200 \mu \mathrm{L}$ of $4 \mathrm{mg} / \mathrm{mL}$ fibrinogen was added to $86.4 \mu \mathrm{L} \mathrm{CaCl}_{2}$ (25 mM stock solution Stago catalog \#00367 STA), $86.4 \mu \mathrm{L}$ phospholipid (solubilized in OK buffer adapted from STA C.K Prest standard kit, Stago catalog \#00597), $16 \mu \mathrm{L}$ OK buffer, and $32.4 \mu \mathrm{L}$ of $1 \mathrm{mg} / \mathrm{mL}$ venom $50 \%$ glycerol stock or $32.4 \mu \mathrm{L} 50 \%$ deionized water/glycerol as a negative control. While the ratio of venom:fibrinogen was not identical to the ratio used in the fibrinogen gels $(1: 10), 1: 6(200 / 32.4=6.17)$ was the maximum ratio for this experimental setup due to cofactor and antivenom volume constraints in the assay. The total volume was $421.2 \mu \mathrm{L}$, with fibrinogen at a final concentration of $1.9 \mathrm{mg} / \mathrm{mL}$ and venom at a concentration of $0.3 \mathrm{mg} / \mathrm{mL}$. These mixtures were then incubated at $37^{\circ} \mathrm{C}$ for $2 \mathrm{~h}$, which was based on results from previous fibrinogen 1D SDS-PAGE gels. After incubation, $360 \mu \mathrm{L}$ was transferred to 'natural pins and cups' (Lot\# HMO3163, Haemonetics Australia Pty Ltd., North Ryde, Sydney 2113, Australia) and $7 \mu \mathrm{L}$ of thrombin was added (from Stago Liquid Fib kit, unknown concentration from supplier (Stago catalog \#115081 Liquid Fib)) to force clotting of the remaining fibrinogen which was measured over a time period of $30 \mathrm{~min}$.

\subsection{Antivenom Efficacy and Statistics}

In a similar fashion as the clotting inhibition tests, these assays used the Thrombelastograph ${ }^{\circledR}$ 5000 Haemostasis analyser (Haemonetics ${ }^{\circledR}$, Haemonetics.com, Cat\# 07-033) as well. This assay used $200 \mu \mathrm{L}$ of $4 \mathrm{mg} / \mathrm{mL}$ fibrinogen, $86.4 \mu \mathrm{L} \mathrm{CaCl}_{2}, 86.4 \mu \mathrm{L}$ phospholipid, $32.4 \mu \mathrm{L}$ of $1 \mathrm{mg} / \mathrm{mL}$ venom $50 \%$ glycerol stock or $32.4 \mu \mathrm{L} \mathrm{50 \%} \mathrm{deionized} \mathrm{water/glycerol} \mathrm{as} \mathrm{a} \mathrm{negative} \mathrm{control,} \mathrm{and} 16 \mu \mathrm{L}$ of previously mentioned $2.6 \%, 7.5 \%$, or $100 \%$ antivenom, resulting in $0.1 \%, 0.3 \%$, and $3.8 \%$ antivenom concentration in the end, respectively. The solution was incubated at $37^{\circ} \mathrm{C}$ for $2 \mathrm{~h}$. Afterward, $360 \mu \mathrm{L}$ was transferred to the cup and $7 \mu \mathrm{L}$ of thrombin was added. Clot-formation parameters were automatically measured over a period of $30 \mathrm{~min}$.

Significance between the venom-only treatment and venom + antivenom treatment was calculated in GraphPad PRISM 7.0 using a t-test. A Shapiro-Wilk normality test gave a $p$-value of 0.66 for the venom treatment and 0.93 for the venom and antivenom treatment. These $p$-values show that the values were not significantly different than a Gaussian distribution, allowing the use of a t-test. Assuming Gaussian distribution, we performed an unpaired t-test with Welch's correction for unequal standard deviations.

\subsection{D Gels of Crude Venom}

In order to investigate the proteomic variation in venoms, 1D gradient gels were run under both reducing and nonreducing conditions using the same gel setup as described above in Section 4.4.

$25 \mu \mathrm{g}$ of venom was diluted in $7.5 \mu \mathrm{L}$ of deionized water and $7.5 \mu \mathrm{L}$ of $2 \times$ Laemmli sample buffer for nonreduced venom and in $7.5 \mu \mathrm{L}$ of deionized water and $7.5 \mu \mathrm{L}$ of $50 \% 2 \times$ Laemmli sample buffer and DTT for reduced samples. Reduced samples were boiled for $4 \mathrm{~min}$ at $100{ }^{\circ} \mathrm{C}$. Nonreduced and reduced samples were loaded on different gels and both gels run with $8 \mu \mathrm{L}$ of unstained ladder. Afterward, gels were stained using colloidal Coomassie brilliant blue and destained overnight using deionized water.

Author Contributions: Conceptualization, B.G.F.; methodology, B.G.F.; investigation, D.G., C.N.Z., J.S.D., N.J.Y., F.C., M.B.-V., A.A., B.G.F.; resources, M.B.-V., A.A., B.G.F.; writing-original draft preparation, D.G., C.N.Z., B.G.F.; writing-review and editing, D.G., C.N.Z., J.S.D., N.J.Y., F.C., M.B.-V., A.A., B.G.F.; D.G., C.N.Z., J.S.D., N.J.Y., F.C., M.B.-V., A.A., B.G.F.; supervision, B.G.F.; project administration, B.G.F.; funding acquisition, B.G.F. All authors have read and agreed to the published version of the manuscript. 
Funding: This work was funded by Australian Research Council Discovery Project DP190100304 to B.G.F.

Conflicts of Interest: The authors declare no conflict of interest.

\section{References}

1. Senff-Ribeiro, A.; Henrique da Silva, P.; Chaim, O.M.; Gremski, L.H.; Paludo, K.S.; Bertoni da Silveira, R.; Gremski, W.; Mangili, O.C.; Veiga, S.S. Biotechnological applications of brown spider (Loxosceles genus) venom toxins. Biotechnol. Adv. 2008, 26, 210-218. [CrossRef] [PubMed]

2. Casewell, N.R.; Wuster, W.; Vonk, F.J.; Harrison, R.A.; Fry, B.G. Complex cocktails: The evolutionary novelty of venoms. Trends Ecol. Evol. 2013, 28, 219-229. [CrossRef] [PubMed]

3. Chaves-Moreira, D.; Senff-Ribeiro, A.; Wille, A.C.M.; Gremski, L.H.; Chaim, O.M.; Veiga, S.S. Highlights in the knowledge of brown spider toxins. J. Venom. Anim. Toxins Incl. Trop. Dis. 2017, 23, 6. [CrossRef] [PubMed]

4. Pauli, I.; Puka, J.; Gubert, I.C.; Minozzo, J.C. The efficacy of antivenom in loxoscelism treatment. Toxicon 2006, 48, 123-137. [CrossRef] [PubMed]

5. Tambourgi, D.V.; Goncalves-de-Andrade, R.M.; van den Berg, C.W. Loxoscelism: From basic research to the proposal of new therapies. Toxicon 2010, 56, 1113-1119. [CrossRef]

6. De Roodt, A.R.; Salomon, O.D.; Lloveras, S.C.; Orduna, T.A. Poisoning by spiders of Loxosceles genus. Medicina (B Aires) 2002, 62, 83-94.

7. Pedroso, A.; Matioli, S.R.; Murakami, M.T.; Pidde-Queiroz, G.; Tambourgi, D.V. Erratum: Adaptive evolution in the toxicity of a spider's venom enzymes. BMC Evol. Biol. 2016, 16, 58. [CrossRef]

8. Chaves-Moreira, D.; Matsubara, F.H.; Schemczssen-Graeff, Z.; De Bona, E.; Heidemann, V.R.; Guerra-Duarte, C.; Gremski, L.H.; Chavez-Olortegui, C.; Senff-Ribeiro, A.; Chaim, O.M.; et al. Brown Spider (Loxosceles) Venom Toxins as Potential Biotools for the Development of Novel Therapeutics. Toxins 2019, 11, 355. [CrossRef]

9. Feitosa, L.; Gremski, W.; Veiga, S.S.; Elias, M.C.; Graner, E.; Mangili, O.C.; Brentani, R.R. Detection and characterization of metalloproteinases with gelatinolytic, fibronectinolytic and fibrinogenolytic activities in brown spider (Loxosceles intermedia) venom. Toxicon 1998, 36, 1039-1051. [CrossRef]

10. Santos, R.M.; Guerra-Duarte, C.; de Almeida Lima, S.; Costal-Oliveira, F.; Alves de Aquino, P.; Oliveira do Carmo, A.; Ferreyra, C.B.; Gonzalez-Kozlova, E.E.; Kalapothakis, E.; Chavez-Olortegui, C. Diversity of astacin-like metalloproteases identified by transcriptomic analysis in Peruvian Loxosceles laeta spider venom and in vitro activity characterization. Biochimie 2019, 167, 81-92. [CrossRef]

11. Stocker, W.; Grams, F.; Baumann, U.; Reinemer, P.; Gomis-Ruth, F.X.; McKay, D.B.; Bode, W. The metzincins-Topological and sequential relations between the astacins, adamalysins, serralysins, and matrixins (collagenases) define a superfamily of zinc-peptidases. Protein. Sci. 1995, 4, 823-840. [CrossRef] [PubMed]

12. Trevisan-Silva, D.; Gremski, L.H.; Chaim, O.M.; da Silveira, R.B.; Meissner, G.O.; Mangili, O.C.; Barbaro, K.C.; Gremski, W.; Veiga, S.S.; Senff-Ribeiro, A. Astacin-like metalloproteases are a gene family of toxins present in the venom of different species of the brown spider (genus Loxosceles). Biochimie 2010, 92, 21-32. [CrossRef] [PubMed]

13. Bittenbinder, M.A.; Zdenek, C.N.; Op den Brouw, B.; Youngman, N.J.; Dobson, J.S.; Naude, A.; Vonk, F.J.; Fry, B.G. Coagulotoxic cobras: Clinical implications of strong anticoagulant actions of african spitting naja venoms that are not neutralised by antivenom but are by LY315920 (Varespladib). Toxins 2018, 10, 516. [CrossRef] [PubMed]

14. Bittenbinder, M.A.; Dobson, J.S.; Zdenek, C.N.; Op den Brouw, B.; Naude, A.; Vonk, F.J.; Fry, B.G. Differential destructive (non-clotting) fibrinogenolytic activity in Afro-Asian elapid snake venoms and the links to defensive hooding behavior. Toxicol. In Vitro 2019, 60, 330-335. [CrossRef]

15. Da Silveira, R.B.; dos Santos Filho, J.F.; Mangili, O.C.; Veiga, S.S.; Gremski, W.; Nader, H.B.; von Dietrich, C.P. Identification of proteases in the extract of venom glands from brown spiders. Toxicon 2002, 40, 815-822. [CrossRef]

16. Zanetti, V.C.; da Silveira, R.B.; Dreyfuss, J.L.; Haoach, J.; Mangili, O.C.; Veiga, S.S.; Gremski, W. Morphological and biochemical evidence of blood vessel damage and fibrinogenolysis triggered by brown spider venom. Blood Coagul. Fibrinolysis 2002, 13, 135-148. [CrossRef] 
17. Trevisan-Silva, D.; Bednaski, A.V.; Gremski, L.H.; Chaim, O.M.; Veiga, S.S.; Senff-Ribeiro, A. Differential metalloprotease content and activity of three Loxosceles spider venoms revealed using two-dimensional electrophoresis approaches. Toxicon 2013, 76, 11-22. [CrossRef]

18. Debono, J.; Bos, M.H.A.; Coimbra, F.; Ge, L.; Frank, N.; Kwok, H.F.; Fry, B.G. Basal but divergent: Clinical implications of differential coagulotoxicity in a clade of Asian vipers. Toxicol. In Vitro 2019, 58, 195-206. [CrossRef]

19. Oulion, B.; Dobson, J.S.; Zdenek, C.N.; Arbuckle, K.; Lister, C.; Coimbra, F.C.P.; Op den Brouw, B.; Debono, J.; Rogalski, A.; Violette, A.; et al. Factor X activating Atractaspis snake venoms and the relative coagulotoxicity neutralising efficacy of African antivenoms. Toxicol. Lett. 2018, 288, 119-128. [CrossRef]

20. Sousa, L.F.; Zdenek, C.N.; Dobson, J.S.; Op den Brouw, B.; Coimbra, F.; Gillett, A.; Del-Rei, T.H.M.; Chalkidis, H.M.; Sant'Anna, S.; Teixeira-da-Rocha, M.M.; et al. Coagulotoxicity of Bothrops (lancehead pit-vipers) venoms from Brazil: Differential biochemistry and antivenom efficacy resulting from prey-driven venom variation. Toxins 2018, 10, 411. [CrossRef]

21. Coimbra, F.C.P.; Dobson, J.; Zdenek, C.N.; Op den Brouw, B.; Hamilton, B.; Debono, J.; Masci, P.; Frank, N.; Ge, L.; Kwok, H.F.; et al. Does size matter? Venom proteomic and functional comparison between night adder species (Viperidae: Causus) with short and long venom glands. Comp. Biochem. Physiol. C Toxicol. Pharmacol. 2018, 211, 7-14. [CrossRef] [PubMed]

22. Dobson, J.S.; Zdenek, C.N.; Hay, C.; Violette, A.; Fourmy, R.; Cochran, C.; Fry, B.G. Varanid lizard venoms disrupt the clotting ability of human fibrinogen through destructive cleavage. Toxins 2019, 11, 255. [CrossRef] [PubMed]

23. Van Aswegen, G.; Van Rooyen, J.M.; Van der Nest, D.G.; Veldman, F.J.; De Villiers, T.H.; Oberholzer, G. Venom of a six-eyed crab spider, Sicarius testaceus (Purcell, 1908), causes necrotic and haemorrhagic lesions in the rabbit. Toxicon 1997, 35, 1149-1152. [CrossRef]

24. Binford, G.J.; Bodner, M.R.; Cordes, M.H.; Baldwin, K.L.; Rynerson, M.R.; Burns, S.N.; Zobel-Thropp, P.A. Molecular evolution, functional variation, and proposed nomenclature of the gene family that includes sphingomyelinase D in sicariid spider venoms. Mol. Biol. Evol. 2009, 26, 547-566. [CrossRef]

25. Pauli, I.; Minozzo, J.C.; da Silva, P.H.; Chaim, O.M.; Veiga, S.S. Analysis of therapeutic benefits of antivenin at different time intervals after experimental envenomation in rabbits by venom of the brown spider (Loxosceles intermedia). Toxicon 2009, 53, 660-671. [CrossRef]

26. Dias-Lopes, C.; Guimaraes, G.; Felicori, L.; Fernandes, P.; Emery, L.; Kalapothakis, E.; Nguyen, C.; Molina, F.; Granier, C.; Chavez-Olortegui, C. A protective immune response against lethal, dermonecrotic and hemorrhagic effects of Loxosceles intermedia venom elicited by a 27-residue peptide. Toxicon 2010, 55, 481-487. [CrossRef]

27. De Moura, J.; Felicori, L.; Moreau, V.; Guimaraes, G.; Dias-Lopes, C.; Molina, L.; Alvarenga, L.M.; Fernandes, P.; Frezard, F.; Ribeiro, R.R.; et al. Protection against the toxic effects of Loxosceles intermedia spider venom elicited by mimotope peptides. Vaccine 2011, 29, 7992-8001. [CrossRef]

28. Duarte, C.G.; Bonilla, C.; Guimaraes, G.; Machado de Avila, R.A.; Mendes, T.M.; Silva, W.; Tintaya, B.; Yarleque, A.; Chavez-Olortegui, C. Anti-loxoscelic horse serum produced against a recombinant dermonecrotic protein of Brazilian Loxosceles intermedia spider neutralize lethal effects of Loxosceles laeta venom from Peru. Toxicon 2015, 93, 37-40. [CrossRef]

29. Lima, S.A.; Guerra-Duarte, C.; Costal-Oliveira, F.; Mendes, T.M.; Figueiredo, L.F.M.; Oliveira, D.; Machado de Avila, R.A.; Ferrer, V.P.; Trevisan-Silva, D.; Veiga, S.S.; et al. Recombinant protein containing B-cell epitopes of different loxosceles spider toxins generates neutralizing antibodies in immunized rabbits. Front. Immunol. 2018, 9, 653. [CrossRef]

30. De Almeida, D.M.; Fernandes-Pedrosa Mde, F.; de Andrade, R.M.; Marcelino, J.R.; Gondo-Higashi, H.; de Azevedo Ide, L.; Ho, P.L.; van den Berg, C.; Tambourgi, D.V. A new anti-loxoscelic serum produced against recombinant sphingomyelinase D: Results of preclinical trials. Am. J. Trop. Med. Hyg. 2008, 79, 463-470. [CrossRef]

31. Newlands, G.; Atkinson, P. Review of southern African spiders of medical importance, with notes on the signs and symptoms of envenomation. S. Afr. Med. J. 1988, 73, 235-239. [PubMed]

32. Rosen, J.L.; Dumitru, J.K.; Langley, E.W.; Meade Olivier, C.A. Emergency department death from systemic loxoscelism. Ann. Emerg. Med. 2012, 60, 439-441. [CrossRef] [PubMed] 
33. Aran-Sekul, T.; Rojas, J.M.; Subiabre, M.; Cruz, V.; Cortes, W.; Osorio, L.; Gonzalez, J.; Araya, J.E.; Catalan, A. Heterophilic antibodies in sera from individuals without loxoscelism cross-react with phospholipase D from the venom of Loxosceles and Sicarius spiders. J. Venom. Anim. Toxins. Incl. Trop. Dis. 2018, 24, 18. [CrossRef] [PubMed]

34. Schwartz, M.L.; Pizzo, S.V.; Hill, R.L.; McKee, P.A. The effect of fibrin-stabilizing factor on the subunit structure of human fibrin. J. Clin. Investig. 1971, 50, 1506-1513. [CrossRef]

35. Gaffney, P.J.; Whitaker, A.N. Fibrin crosslinks and lysis rates. Thromb. Res. 1979, 14, 85-94. [CrossRef]

36. Hemostasis and Thrombosis: Basic Principles and Clinical Practice; Lippincott Williams \& Wilkins: Philadelphia, PA, USA, 2006.

37. Olvera, A.; Ramos-Cerrillo, B.; Estevez, J.; Clement, H.; de Roodt, A.; Paniagua-Solis, J.; Vazquez, H.; Zavaleta, A.; Arruz, M.S.; Stock, R.P.; et al. North and South American Loxosceles spiders: Development of a polyvalent antivenom with recombinant sphingomyelinases D as antigens. Toxicon 2006, 48, 64-74. [CrossRef]

38. Chippaux, J.P. Guidelines for the production, control and regulation of snake antivenom immunoglobulins. Biol. Aujourdhui 2010, 204, 87-91. [CrossRef]

39. Fernandes-Pedrosa Mde, F.; Junqueira-de-Azevedo Ide, L.; Goncalves-de-Andrade, R.M.; Kobashi, L.S.; Almeida, D.D.; Ho, P.L.; Tambourgi, D.V. Transcriptome analysis of Loxosceles laeta (Araneae, Sicariidae) spider venomous gland using expressed sequence tags. BMC Genom. 2008, 9, 279. [CrossRef]

40. Warrell, D.A. Hunter's Tropical Medicine and Emerging Infectious Disease, 9th ed.; Magill, A.J., Hill, D.R., Solomon, T., Ryan, E.T., Eds.; Elsevier: Amsterdam, The Netherlands, 2012; pp. 969-985. [CrossRef]

41. Dobson, J.; Yang, D.C.; Op den Brouw, B.; Cochran, C.; Huynh, T.; Kurrupu, S.; Sanchez, E.E.; Massey, D.J.; Baumann, K.; Jackson, T.N.W.; et al. Rattling the border wall: Pathophysiological implications of functional and proteomic venom variation between Mexican and US subspecies of the desert rattlesnake Crotalus scutulatus. Comp. Biochem. Physiol. C Toxicol. Pharmacol. 2018, 205, 62-69. [CrossRef]

42. Debono, J.; Bos, M.H.A.; Nouwens, A.; Ge, L.; Frank, N.; Kwok, H.F.; Fry, B.G. Habu coagulotoxicity: Clinical implications of the functional diversification of Protobothrops snake venoms upon blood clotting factors. Toxicol. In Vitro 2019, 55, 62-74. [CrossRef]

43. Koludarov, I.; Jackson, T.N.; Brouw, B.O.D.; Dobson, J.; Dashevsky, D.; Arbuckle, K.; Clemente, C.J.; Stockdale, E.J.; Cochran, C.; Debono, J.; et al. Enter the cragon: The dynamic and multifunctional evolution of anguimorpha lizard venoms. Toxins 2017, 9, 242. [CrossRef] [PubMed]

44. Debono, J.; Dobson, J.; Casewell, N.R.; Romilio, A.; Li, B.; Kurniawan, N.; Mardon, K.; Weisbecker, V.; Nouwens, A.; Kwok, H.F.; et al. Coagulating colubrids: Evolutionary, pathophysiological and biodiscovery implications of venom variations between boomslang (Dispholidus typus) and twig snake (Thelotornis mossambicanus). Toxins 2017, 9, 171. [CrossRef] [PubMed]

45. Schneider, C.A.; Rasband, W.S.; Eliceiri, K.W. NIH Image to ImageJ: 25 years of image analysis. Nat. Methods 2012, 9, 671-675. [CrossRef] [PubMed]

(C) 2020 by the authors. Licensee MDPI, Basel, Switzerland. This article is an open access article distributed under the terms and conditions of the Creative Commons Attribution (CC BY) license (http://creativecommons.org/licenses/by/4.0/). 